\title{
Lipid-coated gold nanocomposites for enhanced cancer therapy
}

\author{
This article was published in the following Dove Press journal: \\ International Journal of Nanomedicine \\ 25 August 2015 \\ Number of times this article has been viewed
}

\section{Ji Hee Kang \\ Young Tag Ko}

College of Pharmacy, Gachon

University, Incheon, Republic of Korea
Abstract: The aim of the work reported here was to develop lipid-coated multifunctional nanocomposites composed of drugs and nanoparticles for use in cancer therapy. We incorporated thermosensitive phospholipids onto the surface of anisotropic gold nanoparticles (AuNPs) to further enhance drug delivery, with possible additional applications for in vivo imaging and photothermal cancer therapy. Lipid-coated nanohybrids loaded with the drug docetaxel (DTX) were prepared by a thin-film formation, hydration, and sonication method. Nanoparticles and their composites were characterized using particle-size analysis, zeta potential measurements, transmission electron microscopy, UV-visible spectroscopy, and reverse-phase high-performance liquid chromatography, demonstrating successful loading of DTX into the lipid bilayer on the surface of the gold nanoparticles. Initial in vitro studies using breast-cancer (MCF-7) and melanoma (B16F10) cell lines demonstrated that the drug-containing nanocomposites at equivalent drug concentrations caused significant cytotoxicity compared to free DTX. Differential flow cytometry analysis confirmed the improved cellular uptake of lipid-coated nanocomposites. Our preliminary results show that DTX-loaded anionic lipid-coated gold nanorod (AL_AuNR_DTX) and cationic lipid-coated gold nanoparticle (CL_AuNP_DTX) possess effective tumor cellsuppression abilities and can therefore be considered promising chemotherapeutic agents. Further evaluation of the therapeutic efficacy of these hybrid nanoparticles combined with external near-infrared photothermal treatment is warranted to assess their synergistic anticancer actions and potential bioimaging applications.

Keywords: thermosensitive lipids, gold nanorods, docetaxel, drug-containing nanocomposites, anticancer

\section{Introduction}

There is a vital need for less invasive but more efficient cancer treatments to reduce the severe adverse effects caused by the currently available therapies, driving the development of alternative drug-delivery systems. ${ }^{1}$ In particular, nanotechnologybased platforms, such as micelles, polymers, liposomes, solid lipid nanoparticles, and metal nanoparticle-conjugated biodegradable systems, have been proposed for use in improved cancer chemotherapy. Liposomes are the simplest artificial biological cells, with potential uses in drug delivery, molecular imaging, and gene therapy, as well as for applications such as artificial blood and cell membranes. ${ }^{2}$ Liposomal nanoparticles are made up of natural lipids, usually phospholipids and cholesterol, which encapsulate water-soluble or water-insoluble drugs in their hydrophilic or hydrophobic core, respectively. They are designed for the controlled delivery of imaging and therapeutic agents, thereby enhancing pharmacokinetic processes to maximize therapeutic efficacy and minimize side effects. Active and passive targeting of liposomes are extensively utilized for the enhanced permeability and retention (EPR) effect and ligand conjugation. ${ }^{3-5}$ Thermosensitive liposomes are commonly used as drug carriers,
Correspondence: Young Tag Ko

College of Pharmacy, Gachon University,

191 Hambakmoero, Yeonsu-gu, Incheon

406-799, Republic of Korea

Tel +82 328996417

Fax +82328204829

Email youngtakko@gachon.ac.kr submit your manuscript | www.dovepress.com

Dovepress

http://dx.doi.org//0.2147/IJN.S88307
International Journal of Nanomedicine 2015:10 (Special Issue on diverse applications in Nano-Theranostics) 33-45 33 (c) (i) (5) 2015 Kang and Ko. This work is published by Dove Medical Press Limited, and licensed under Creative Commons Attribution - Non Commercial (unported, v3.0) License. The full terms of the License are available at http://creativecommons.org/licenses/by-nd/3.0/. Non-commercial uses of the work are permitted without any further permissin how to request permission may be found at: http://www.dovepress.com/permissions.php 
and function through externally thermo-stimulated content release. Photosensitive liposomes are commonly triggered to release loaded drugs after reaching a lower critical solution temperature. However, the mechanism employed to release the drug in a controlled manner is of utmost importance for this nanoparticle drug-delivery system.

In recent decades, the use of anisotropic gold in the form of nano-sized particles has attracted much attention among researchers because of the particles' unique optical, electronic, size- and shape-dependent, and chemical properties, which are completely different from those in bulk and elemental form. ${ }^{6-8}$ In particular, gold nanoparticles (AuNPs) strongly absorb light energy, and the gold crystal lattice converts it into homogenous heat energy, which dissipates to the surrounding medium in a picosecond time scale via phonon-phonon relaxation, making nanogold a promising photothermal agent. ${ }^{9-12}$ For these reasons, AuNPs are currently the subject of intense research for potential clinical applications. ${ }^{13}$

Encapsulation or coating of metallic nanoparticles with lipids is a useful non-covalent approach to stabilizing surface chemistry and increasing biocompatibility, which is determined by the structural components present in the cellular membrane. ${ }^{14-19}$ In the study reported here, we aimed to enhance the therapeutic effects of docetaxel (DTX) and reduce its side effects by formulating it in a lipid bilayer on the nanoparticles. Initially, gold nanorods (AuNRs) and AuNPs were prepared by seed-mediated and citrate-stabilized methods, respectively. ${ }^{20-24} \mathrm{~A}$ thermosensitive lipid was coated with DTX by a thin-film formation, hydration, and sonication method. The nanoparticles were then characterized using different analytical techniques to evaluate their size, size distribution index, surface charge, surface morphology, drug encapsulation efficiency, and drug-release profile. In vitro cytotoxicity and quantitative and qualitative cellular uptake in different cancer cells were assessed to evaluate the feasibility of using the two types of DTX-loaded systems for cancer therapy. Additionally, cell-cycle arrest response to the DTX released from the nanocomposites was monitored and visualized using microscopy.

\section{Materials and methods Materials}

DTX with purity of $98 \%$ was purchased from Tokyo Chemical Industry Co, Ltd (Tokyo, Japan). Cetyltrimethylammonium bromide (CTAB), sodium borohydride $\left(\mathrm{NaBH}_{4}\right)$, silver nitrate $\left(\mathrm{AgNO}_{3}\right)$, ascorbic acid, and hydrogen tetrachloroaurate (III) trihydrate $\left(\mathrm{HAuCl}_{4} \cdot 3 \mathrm{H}_{2} \mathrm{O}\right)$ were purchased from
Sigma-Aldrich Co (St Louis, MO, USA). Bovine serum albumin (molecular weight [MW] 66,000 Da) and 3-(4,5dimethylthiazol-2-yl)-2,5-diphenyl tetrazolium bromide (MTT) were procured from Sigma-Aldrich Co. Cholesterol, 1,2-dipalmitoyl-sn-glycero-3-phosphocholine (DPPC), 1,2dihexadecanoyl-sn-glycero-3-phospho-(1'-rac-glycerol) (DPPG), 1,2-dioleoyl-3-trimethylammonium-propane (DOTAP), and 1,2-dimyristoyl-sn-glyero-3-phosphoethanolamine-N-[methoxy (polyethylene glycol)-2000] (PEG2kDSPE) were purchased from Avanti Polar Lipids (Alabaster, AL, USA). All other chemicals were of reagent grade and were used as supplied.

\section{Preparation of AuNRs}

AuNRs were prepared by a modified seed-mediated method described elsewhere. ${ }^{25}$ Initially, the seed solution was prepared by mixing $250 \mu \mathrm{L}$ of $0.01 \mathrm{M} \mathrm{HAuCl}_{4}$ with $7.5 \mathrm{~mL}$ of $0.1 \mathrm{M} \mathrm{CTAB}$ and $600 \mu \mathrm{L}$ of ice-cold $0.01 \mathrm{M} \mathrm{NaBH}_{4}$ under vigorous stirring at room temperature. The growth solution was prepared by adding $400 \mu \mathrm{L}$ of $0.01 \mathrm{M} \mathrm{HAuCl}_{4}, 64 \mu \mathrm{L}$ of $0.1 \mathrm{M}$ ascorbic acid and $35.6 \mu \mathrm{L}$ of $0.1 \mathrm{M} \mathrm{AgNO}_{3}$ to $9.5 \mathrm{~mL}$ of $0.1 \mathrm{M}$ CTAB. Finally, $10 \mu \mathrm{L}$ of 2.5 -hour-old seed solution was added to the solution, and the mixture was left for 24 hours at ambient temperature.

In this synthesis protocol, $\mathrm{AgNO}_{3}$ allowed better control of the resulting shapes in the AuNR formation, while ascorbic acid functioned as a reducing agent.

\section{Preparation of AuNPs}

Citrate-capped AuNPs were synthesized according to the method developed by Frens with minor modifications. ${ }^{26}$ Briefly, $1.214 \mathrm{~mL}$ of $0.01 \mathrm{M} \mathrm{HAuCl}_{4}$ was added to $50 \mathrm{~mL}$ of Milli-Q ${ }^{\circledR}$ water, and the solution was heated to boiling. Next, $1.7 \mathrm{~mL}$ of $0.01 \mathrm{M}$ trisodium citrate trihydrate was added to the solution. The solution was subsequently refluxed for 30 minutes as a color change from dark blue to red was observed. After cooling to room temperature, the solution was filtered $(0.22 \mu \mathrm{m}$ filter $)$ and stored at $4^{\circ} \mathrm{C}$ until use.

\section{Preparation of lipid-encapsulated gold nanocomposites}

For anionic lipid coating, DPPC (18 $\mu \mathrm{mol})$, DPPG $(3 \mu \mathrm{mol})$, cholesterol $(9 \mu \mathrm{mol})$, and PEG2K-DSPE $(0.9 \mu \mathrm{mol})$ lipids were dissolved together in chloroform, followed by the removal of the chloroform using a rotary evaporator at $50^{\circ} \mathrm{C}$. CTAB-removed AuNR solution was prepared as previously reported $^{27}$ and then added to the cationic lipid film dried overnight under vacuum, and the mixture was incubated at 
$50^{\circ} \mathrm{C}$ for 4 hours with intermittent mixing, resulting in a final lipid concentration of $30 \mathrm{mM}$. The suspension was ultrasonicated (Vibra Cell ${ }^{\mathrm{TM}}, 130 \mathrm{~W}, 20 \mathrm{kHz}$ ) using a 2-minute cycle while maintaining the lipids above the phase-transition temperature $\left(\mathrm{T}_{\mathrm{m}}\right)$ of $60^{\circ} \mathrm{C}$. For cationic lipid coating, DPPC (18 $\mu \mathrm{mol})$, DOTAP $(3 \mu \mathrm{mol})$, cholesterol $(9 \mu \mathrm{mol})$, and PEG2k-DSPE $(0.9 \mu \mathrm{mol})$ were used to coat the AuNPs as described earlier.

The anionic lipid-coated drug-loaded AuNR formulation is referred to as AL_AuNR_DTX hereafter, while the cationic lipid-coated nanoparticle formulation is referred as CL_AuNP_DTX.

\section{Particle characterization}

The size, polydispersity, and zeta potential of the liposomes were measured using dynamic light scattering. The lipid-coated formulations were examined after they were suitably diluted with distilled water, and particle characteristics were measured at $25^{\circ} \mathrm{C}$ in an ELSZ-1000 Zeta-Potential and Particle-Size Analyzer (Otsuka Electronics, Osaka, Japan). The absorbance spectra of the uncoated and lipid-coated nanocomposites were recorded in the UV-visible (Vis)-near-infrared region using a Varian Cary ${ }^{\circledR} 50$ UV-Vis Spectrophotometer (Varian, Inc, Palo Alto, CA, USA) with a quartz cell. Morphologies of the two formulations were studied using a Tecnai ${ }^{\text {TM }}$ G2 TF 30ST high-resolution transmission electron microscope.

\section{Determination of drug encapsulation efficiency}

The drug-loading and encapsulation efficiency of the prepared formulations were determined by high-performance liquid chromatography (HPLC) after ultrafiltration using an Amicon ${ }^{\circledR}$ centrifugal filter device (molecular weight cut off [MWCO] 10,000 Da; EMD Millipore, Billerica, MA, USA). Filtered samples $(20 \mu \mathrm{L})$ were injected onto a C18 column (Sepax BR-C18; $5 \mu \mathrm{m} 120 \AA 4.6 \times 150.0 \mathrm{~mm}$ ). The mobile phase was composed of acetonitrile and water $(50: 50, \mathrm{v} / \mathrm{v})$ with a flow rate of $1.0 \mathrm{~mL} / \mathrm{min}$. The amount of DTX in the filtrate was determined using HPLC with a UV-Vis detector at $230 \mathrm{~nm}$. The calibration curve was linear in the range of $5-500 \mu \mathrm{g} / \mathrm{mL}$ with a correlation coefficient of $R^{2}=0.999$. The drug encapsulation efficiency was calculated from the ratio of the amount of DTX encapsulated in the lipid layer of the formulations to the total amount added in the formulation.

\section{In vitro drug-release measurement}

The dialysis-bag diffusion method was used to study the in vitro drug release from the lipid-coated nanocomposites.
Drug-loaded samples equivalent to $200 \mu \mathrm{g}$ of DTX were placed in the dialysis bag (cellulose membrane, MWCO $1,000 \mathrm{Da}$ ), sealed tightly, and immersed into $20 \mathrm{~mL}$ of phosphate-buffered saline (PBS; pH 7.4). The entire system was kept at ambient temperature with continuous shaking at $100 \mathrm{rpm} / \mathrm{min}$. At predetermined time intervals, samples were collected and the withdrawn volume replaced with fresh medium. Sink conditions were maintained throughout the release studies by adding $0.1 \%(\mathrm{w} / \mathrm{v})$ Tween ${ }^{\circledR} 80$ to the release medium because the drug DTX has low solubility in PBS ( $\mathrm{pH}$ 7.4). Collected samples were filtered through a $0.45 \mu \mathrm{m}$ syringe filter and transferred into a HPLC vial.

The concentration of DTX in each sample was measured by liquid chromatography-tandem mass spectrometry (LC-MS/MS) using an Agilent 1260 series HPLC system (Agilent Technologies Inc, Santa Clara, CA, USA) connected to an Agilent 6490 Triple Quadrupole mass spectrometer equipped with an electrospray ionization Agilent Jet Stream ion source. The mobile phase, consisting of $0.1 \%$ formic acid:acetonitrile (1:1), was run at a flow rate of $0.2 \mathrm{~mL} / \mathrm{min}$. Paclitaxel was used as an internal standard. The following mass spectrometry ionization parameters were used: positive electrospray ionization mode, argon collision gas, $5 \mathrm{kV}$ capillary voltage, $225^{\circ} \mathrm{C}$ gas temperature, $15.1 \mathrm{~L} / \mathrm{min}$ gas flow, $22 \mathrm{eV}$ collision energy for DTX, $30 \mathrm{eV}$ collision energy for paclitaxel, and $40^{\circ} \mathrm{C}$ source temperature. Analytes were quantified using multiple reaction monitoring to monitor the ion transitions of $\mathrm{m} / \mathrm{z} 830.3 \rightarrow 303.9$ for DTX and $\mathrm{m} / \mathrm{z}$ of $876.3 \rightarrow 308.0$ for paclitaxel. The range of linear response was $5-500 \mathrm{ng} / \mathrm{mL}$ with $R^{2}=0.9991$.

\section{Cellular uptake of nanocomposites}

The cellular uptake of nanoparticles and their corresponding formulations was evaluated in B16F10 mouse-melanoma and MCF-7 breast-cancer cell lines.

\section{Qualitative analysis by flow cytometry}

A BD FACSCalibur ${ }^{\mathrm{TM}}$ (BD Biosciences, San Jose, CA) flow cytometer consisting of a $488 \mathrm{~nm}$ laser, forward scatter (FSC) diode detector, and a photomultiplier tube side-scatter (SSC) detector was used for the qualitative study. The basic concept of this experiment is that morphologically altered cells will scatter the laser light differently in the FSC and SSC directions. Therefore, we report here that cells with internalized nanoparticles increased the scatter of $488 \mathrm{~nm}$ laser light in the $90^{\circ}$ direction. Initially, B16F 10 and MCF-7 cells were seeded to achieve a confluency of $3 \times 10^{5}$ cells under tissue-culture conditions. They were incubated with uncoated and lipid-coated 
nanocomposite formulations for 1 hour at $37^{\circ} \mathrm{C}$ and washed twice with PBS to remove unbound nanocomposites. The cells were then detached using $0.25 \%$ trypsin/ethylenediaminetetraacetic acid (EDTA) and centrifuged twice at 1,500 rpm for 3 minutes, after which the pellet was resuspended in $500 \mu \mathrm{L}$ of PBS. Suspended cells were directly introduced into the BD FACSCalibur flow cytometer. The cytometer was set up to measure SSC logarithmically and FSC linearly.

Additionally, for comparison, we evaluated the scatter pattern of the same cell samples following incubation with nanocomposite formulations attached to a fluorescence probe (rhodamine) using log amplifiers. The dynamic ranges of the photomultiplier tubes were optimized to obtain the highest sensitivity to changes with the uncoated and coated nanocomposites used. Untreated cells were used as an internal control.

\section{Confocal laser scanning microscopy (CLSM) observation}

Cells were grown on sterile coverslips and allowed to reach $50 \%$ confluence. The cell medium was then replaced with fresh medium containing the lipid-coated gold nanocomposites. Cellular binding and uptake of nanocomposites were imaged with a confocal laser scanning microscope (A1+, Nikon Corporation, Tokyo, Japan) with attached digital camera and software to capture and store images.

\section{Quantitative analysis by LC-MS/MS}

For quantitative study, confluent B16F10 and MCF-7 cells were incubated with lipid-coated nanocomposites in the Dulbecco's Modified Eagle's Medium supplemented with 10\% HyClone ${ }^{\mathrm{TM}}$ fetal bovine serum (Thermo Fisher Scientific, Waltham, MA, USA) and 1\% Invitrogen Gibco ${ }^{\circledR}$ penicillin-streptomycin (Thermo Fisher Scientific) at $37^{\circ} \mathrm{C}$ for 30 minutes, 1 hour, or 3 hours. At designated time points, the suspension was removed, and the wells were washed three times with cold PBS. The trypsinized and centrifuged pellet was subsequently sonicated using 30 cycles of Bioruptor ${ }^{\circledR}$ ultrasonic treatment, active every 10 seconds for a 10 -second duration at $200 \mathrm{~W}$, in an ice bath. The supernatant was collected and extracted for the measurement of drug concentration using LC-MS/MS as previously reported ${ }^{28}$ (linear range $2.5-250.0 \mathrm{ng} / \mathrm{mL}$ with $R^{2}=0.9972$ ).

\section{Cytotoxicity assay}

The cytotoxicity of free DTX, blank liposomes, bare nanoparticles, AL_AuNR_DTX, and CL_AuNP_DTX was assessed using MTT assay. Briefly, $1 \times 10^{4}$ B16F10 mouse-melanoma cells or MCF-7 breast-cancer cells were seeded in 96-well plates at optimal conditions. Following 1 day, the medium was removed, and a range of concentrations of free DTX, blank liposomes, AuNP, AuNR, and two different nanocomposite formulations were added to the cells. Following incubation for 24 hours at $37^{\circ} \mathrm{C}$, the cells were washed twice with PBS then incubated with MTT solution (in serum-free medium) for 2 hours at $37^{\circ} \mathrm{C}$ in the dark. Following cells lysis, formazan crystals were extracted by the addition of dimethyl sulfoxide (DMSO), and the absorbance was measured at $570 \mathrm{~nm}$ using a microplate reader.

\section{Cell-cycle analysis by flow cytometry}

Both cancer cell lines were seeded into six-well plates at a density of $1 \times 10^{6}$ and incubated for 24 hours. The cells were then treated with AuNP, AuNR, AL_AuNR_DTX, or CL_AuNP_ DTX. The cells were trypsinized, harvested, and centrifuged at 3,000 rpm for 3 minutes at $4^{\circ} \mathrm{C}$. The cell pellets were then washed with ice-cold PBS, fixed with $70 \%$ cold ethanol, and incubated on ice for 1 hour. Cell suspension was then treated with $10 \mathrm{mg} / \mathrm{mL}$ of deoxyribonuclease-free ribonuclease $\mathrm{A}$ and stained with $1 \mathrm{mg} / \mathrm{mL}$ solution of propidium iodide for 30 minutes in the dark. The cell-cycle pattern was analyzed, and the number of cells resident in each phase of the cell cycle evaluated using flow cytometry (BD FACSCalibur).

\section{Statistical analysis}

Data are expressed as means and standard errors. Statistical significance was determined using analysis of variance or $t$-test. $P<0.05$ was considered statistically significant.

\section{Results and discussion}

DTX is a strong antimitotic agent which can inhibit both cell proliferation and cell apoptosis in a broad spectrum of cancers. However, therapy with DTX alone causes unwanted systemic toxicity, including bone-marrow suppression, peripheral neuropathy, hypersensitivity reactions, and musculoskeletal disorders. Additionally, multidrug resistance greatly affects the therapeutic efficacy of DTX and limits the delivery of a therapeutic dose..$^{29,30}$ Colloidal nanoparticle-based drug delivery has been considered as a potential tool with remarkable abilities in cancer imaging and therapeutics. ${ }^{31-36}$ Encapsulating nanoparticles in lipid vehicles is an alternative approach that has been used in recent years to achieve controlled drug delivery and implement combined therapy. Therefore, the co-delivery of drug and nanoparticle is becoming a standard strategy in cancer therapy, since it substantially reduces the necessary DTX dose and improves 
its therapeutic efficacy by promoting synergistic activity and reducing drug resistance.

Here, we present our study of polyethylene glycolcontaining lipid-coated nanoparticles that offer effective tumor cell delivery of drugs and can thereby inhibit cell proliferation. Our objective was to enhance the cellular uptake of two different therapeutic carriers and to increase the synergistic action of the entire delivery system.

\section{Preparation and characterization of DTX-loaded lipid-gold nanocomposites}

Initially, AuNPs and AuNRs were prepared with an average particle size of 35.1 and $39.3 \mathrm{~nm}$, respectively, and a narrow size distribution (polydispersity index $[\mathrm{PDI}]=0.2$ and 0.4 , respectively). The gold nanocomposite formulations were prepared by a thin-film hydration-sonication technique (Figure 1). Lipid film containing the hydrophobic drug DTX was hydrated with the nanoparticle dispersions and sonicated. The resulting nanocomposites consisted of a polyethylene glycol-grafted phospholipid layer surrounding AuNPs, in which the lipid acted as a non-associated surface-coating layer. On the other hand, phospholipids formed a stable lipid bilayer on the surface of AuNRs after exchange with a CTAB layer. ${ }^{27,37}$ Lipid coating with DTX on nanoparticles was performed to achieve higher drug encapsulation, controlled drug release, and improved stability of the formulations.

The UV-Vis-near-infrared spectra of AuNPs and AuNRs were characterized by their intense plasmon resonance peaks at 520 and $600 \mathrm{~nm}$, respectively (Figure 2Aa and b). Additionally, the optical properties of both AuNPs were altered with surface modifications. Bathochromic shifts were observed for nanoparticles along with the DTX peak approximately $230 \mathrm{~nm}$. This observation confirms the successful passivation of a drug-loaded lipid bilayer on the surface of the nanoparticles (Figure 2Ac).

Dynamic light scattering showed that the average particle sizes of CL_AuNP_DTX and AL_AuNR_DTX were 70 \pm 0.36 and $49.9 \pm 0.25 \mathrm{~nm}$ (Table 1), with a PDI of 0.21 and 0.47 , respectively. Moreover, the loading of DTX within the lipid layer slightly increased the size of the nanocomposites, with a uniform size distribution compared to their uncoated form. The zeta potential of the uncoated AuNPs was approximately -27 $\mathrm{mV}$, with the negative surface charge most likely reflecting citrate stabilization on the Au core. AuNRs, on the other hand, exhibited a surface charge of approximately $54 \mathrm{mV}$, because of the presence of a bilayer $\mathrm{CTAB}$ structure as a surfactant. The zeta potential of blank cationic liposomes (CL_B) and anionic liposomes (AL_B) was 13.78 and $-19.2 \mathrm{mV}$, respectively.

Compared to the uncoated nanoparticles and blank liposomes, the nanocomposite formulations exhibited charge reversals of $-9.78 \mathrm{mV}$ for CL_AuNP_DTX and $27.41 \mathrm{mV}$ for AL_AuNR_DTX, which could be attributed to the successful surface passivation of the lipid layer around the nanoparticles.

\section{Morphology analysis}

Morphologies of two differently shaped nanoparticles before and after lipid coating were evaluated by transmission electron microscopy imaging in the dried state after

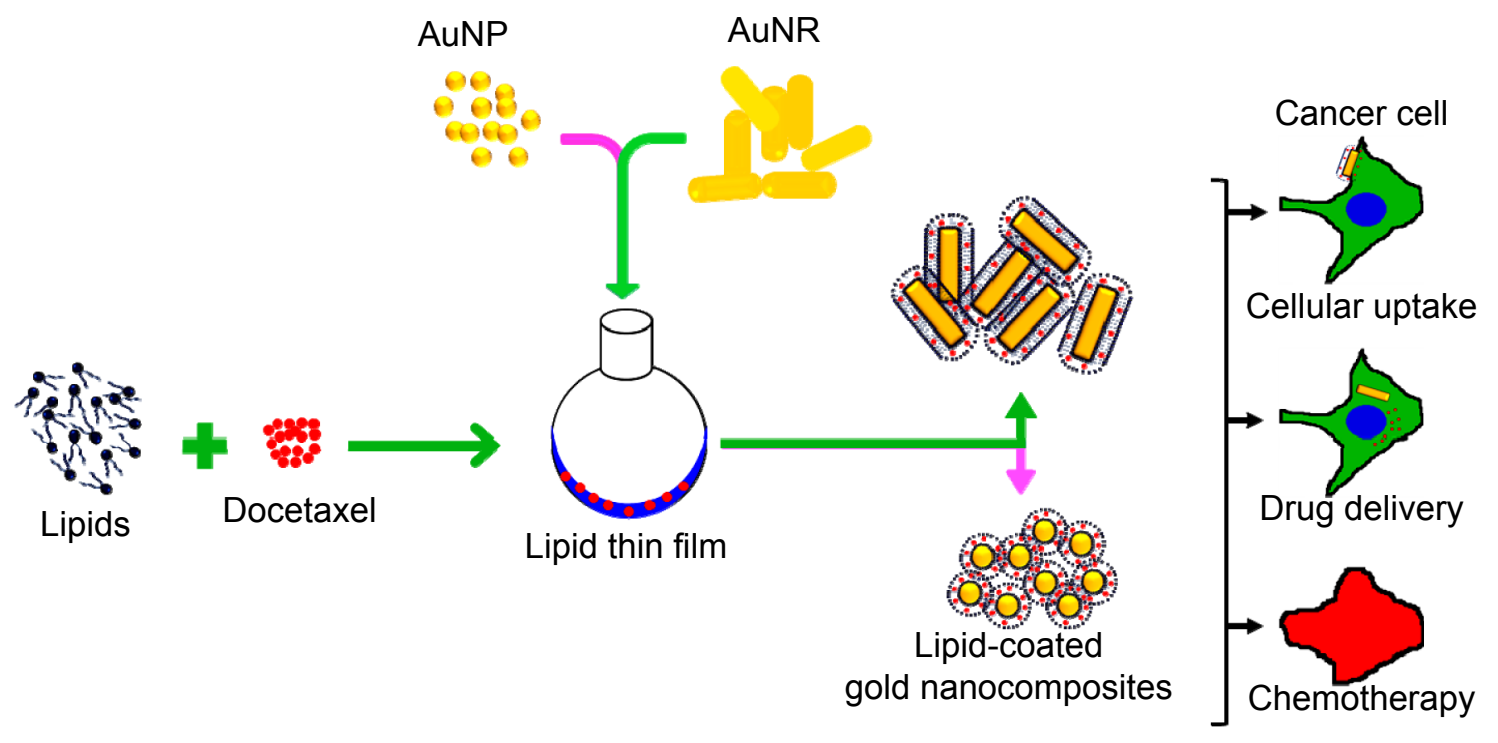

Figure I The gold nanocomposite formulations were prepared by a thin-film hydration-sonication technique. Abbreviations: AuNR, gold nanorod; AuNP, spherical gold nanoparticle. 

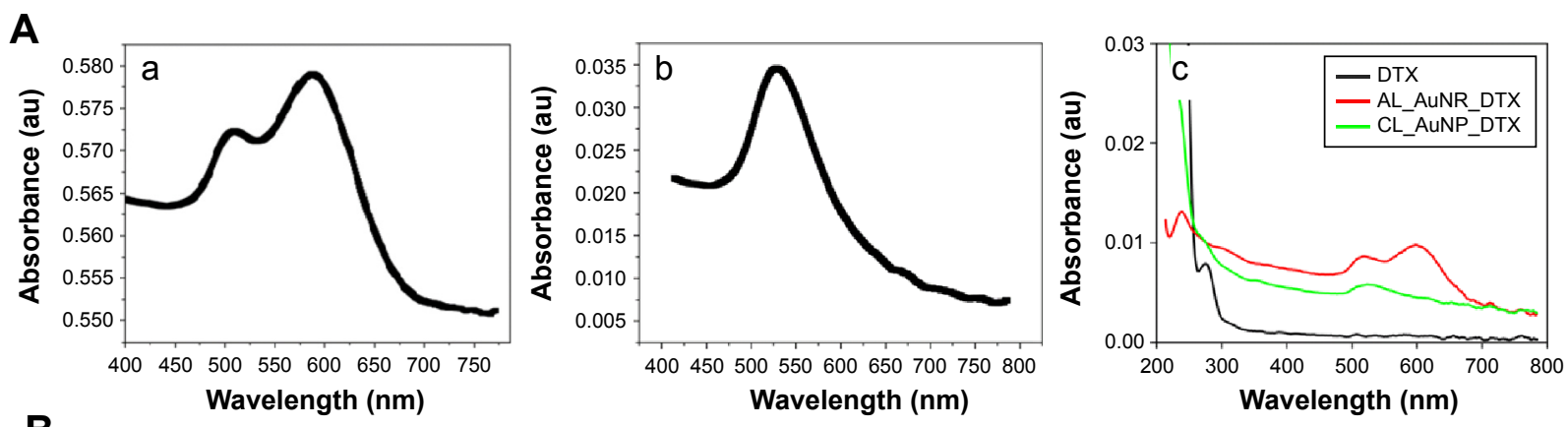

B
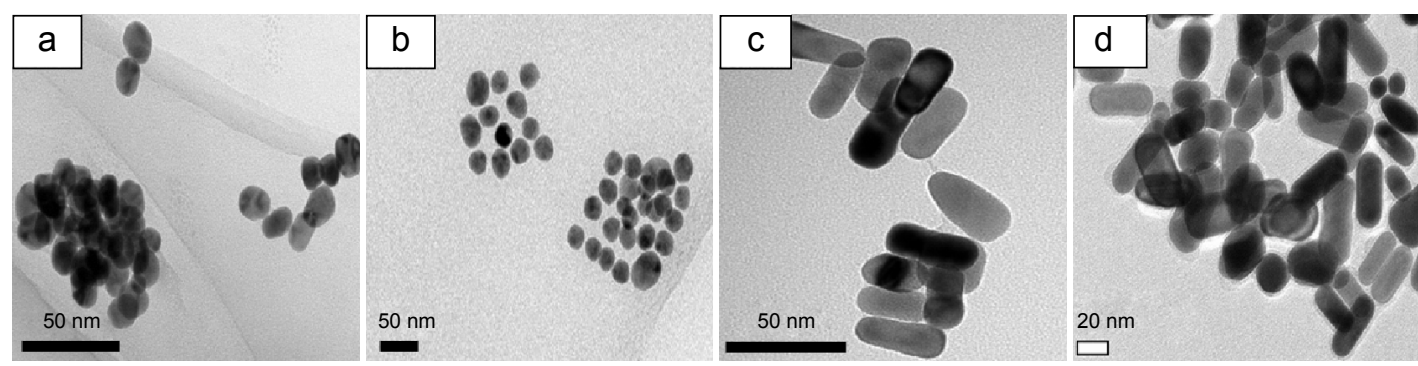

Figure 2 Characterization data of gold nanocomposites as determined by transmission electron microscopy (TEM) and UV-visible spectrophotometry.

Notes: (A) UV-visible spectroscopy of (a) AuNR, (b) AuNP, and (c) CL_AuNP_DTX and AL_AuNR_DTX. (B) TEM images of (a) AuNP, (b) CL_AuNP_DTX, (c) AuNR, and (d) AL_AuNR_DTX.

Abbreviations: AL_AuNR_DTX, docetaxel-loaded anionic lipid-coated gold nanorod; AuNP, spherical gold nanoparticle; AuNR, gold nanorod; CL_AuNP_DTX, cationic lipid-coated gold nanoparticle.

staining with 2\% phosphotungstic acid (Figure 2B). As can be seen, the spherically shaped nanoparticles and rodshaped nanoparticles were distinct and uniformly dispersed (Figure 2Ba and $\mathrm{c}$ ). The lipid layer acted as a template as well as a stabilizer, which retained the in situ reduced AuNPs without undergoing any aggregation. After lipid coating, the AuNPs showed a discrete arrangement, whereas the AuNRs formed aggregates. The observed aggregation was most likely a result of the rapid removal of water during the drying process (Figure $2 \mathrm{Bb}$ and $\mathrm{d}$ ). While there was no clear distinction between the lipid layer and the AuNP surface - which could possibly be due to the close/longitudinal attachment of the lipid layer - monodispersity was maintained. In the evaluation of nanorods, a thin lipid layer was observed around each particle, covering the entire particle. This observation further confirmed that the attachment of a lipid layer around the nanoparticle surface did not alter the existing morphology, thereby maintaining its intact shape.

Hobbs et al reported that tumor tissues exhibit impaired lymphatic drainage and interstitial spaces. ${ }^{38}$ Nanoparticles with smaller sizes $(<200 \mathrm{~nm})$ therefore have preferential access and can accumulate in the tumor region via the EPR effect. The nanocomposites evaluated in the present study are thus capable of permeating through the EPR effect to reach cancer cells. ${ }^{38,39}$

\section{Determination of drug-loading efficiency}

Drug encapsulation efficiencies of the formulations, as determined by HPLC analysis, were found to be $95.700 \% \pm 0.011 \%$

Table I Physicochemical characteristics of different shaped gold nanoparticles, blank liposomes, and drug-loaded lipid-coated gold nanocomposites

\begin{tabular}{llllll}
\hline Sample & Size $(\mathbf{n m})$ & Polydispersity index & Zeta potential $(\mathbf{m V})$ & Encapsulation efficiency (\%) & Loading capacity (\%) \\
\hline AuNR & $35.10 \pm 11.20$ & $0.400 \pm 0.050$ & $54.10 \pm 14.20$ & - & - \\
AL_B & $127.20 \pm 2.7 \mathrm{I}$ & $0.083 \pm 0.021$ & $-19.20 \pm 0.43$ & - & - \\
AL_AuNR_DTX & $49.90 \pm 0.25$ & $0.470 \pm 0.010$ & $27.40 \pm 1.52$ & $81.670 \pm 0.013$ & $8.06 \pm 0.21$ \\
AuNP & $39.30 \pm 9.30$ & $0.210 \pm 0.070$ & $-27.33 \pm 10.50$ & - & - \\
CL_B & $112.60 \pm 11.20$ & $0.031 \pm 0.020$ & $13.78 \pm 11.12$ & - & - \\
CL_AuNP_DTX & $70.0 \pm 7.36$ & $0.210 \pm 0.021$ & $-9.78 \pm 0.68$ & $95.700 \pm 0.011$ & $9.12 \pm 0.13$ \\
\hline
\end{tabular}

Note: Data are expressed as mean \pm standard deviation $(n=3)$.

Abbreviations: AL_AuNR_DTX, DTX-loaded anionic lipid-coated gold nanorod; AL_B, anionic liposome; AuNP, spherical gold nanoparticle; AuNR, gold nanorod; CL_AuNP_DTX, cationic lipid-coated gold nanoparticles; CL_B, cationic liposomes. 
and $81.670 \% \pm 0.013 \%$ for CL_AuNP_DTX and AL_AuNR DTX, respectively (Table 1). Inclusion of cholesterol increased the amount of DTX loading in the formulation, because the added cholesterol reduced the fluidity and increased the stability of the bilayer membranes formed by DPPC lipids. ${ }^{40}$ Lipid-encapsulated AuNP formulations showed increased drug encapsulation compared with the formulations containing AuNRs. This difference may be due to disparities in surface morphology and the size of the particles used. The encapsulation efficiency of the AuNRs was lower with AL_AuNR_DTX formulations, possibly because the bilayer microstructures present in the lipids were changed by the addition of AuNRs and the AuNRs occupied additional space in the lipids. Therefore, AuNRs were embedded in the spaces of the lipids because of their elongated shape, leading to decreased DTX encapsulation. Considering the drug encapsulation efficiency, spherical-shaped AuNPs appear to be the optimal nanoparticles for the encapsulation of drugs through lipid encapsulation.

\section{In vitro drug-release study}

Figure 3 shows the accumulated percentage release of DTX from the nanocomposite formulations in the PBS medium containing $0.1 \% \mathrm{w} / \mathrm{v}$ Tween 80 . Both formulations showed a controlled release of DTX for longer than 24 hours, compared to the burst release observed with free DTX. After 1 day, $\sim 70 \%$ and $\sim 41 \%$ of the loaded DTX was released from the CL_AuNP_DTX and AL_AuNR_DTX formulations, respectively. Finally, a total of approximately $75 \%$ and $45 \%$ of DTX was released from CL_AuNP_DTX and AL_AuNR_DTX,

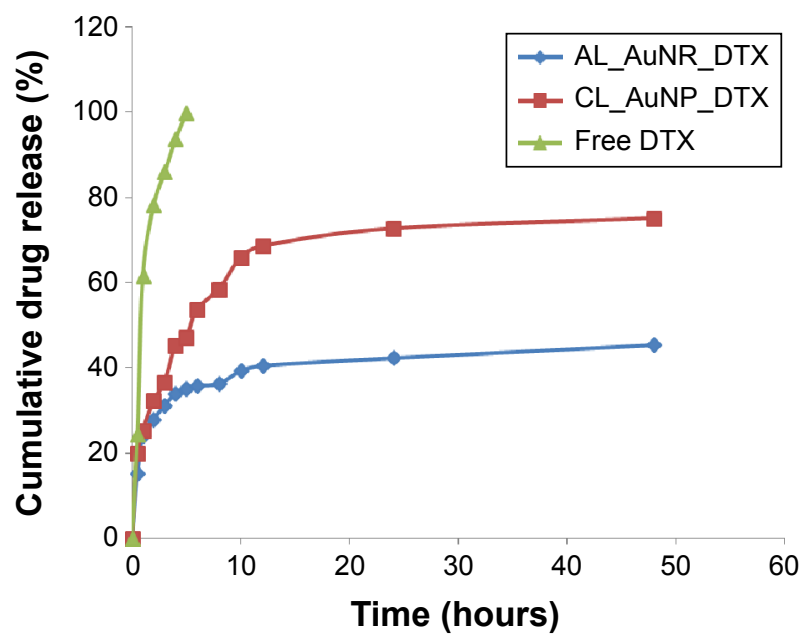

Figure 3 In vitro release profiles of DTX from AL_AuNR_DTX, CL_AuNP_DTX, and free DTX in phosphate-buffered saline $(\mathrm{pH} 7.4,0.14 \mathrm{M} \mathrm{NaCl})$ at $37^{\circ} \mathrm{C}$. Abbreviations: AL_AuNR_DTX, docetaxel-loaded anionic lipid-coated gold nanorod; CL_AuNP_DTX, cationic lipid-coated gold nanoparticle; DTX, docetaxel. respectively, at the end of the 48-hour study period, which is comparable to various other formulations for DTX delivery, as approximately $70 \%$ of DTX is released from these within 48 hours. ${ }^{41,42}$ The CL_AuNP_DTX system showed significantly higher in vitro release than the AL_AuNR_DTX system $(P<0.05)$. The higher percentage of drug release obtained from the CL_AuNP_DTX system may be explained by the influence of the surface area of the AuNPs used. The monodispersed AuNP formulation (CL_AuNP_DTX) could interact with the release media because of its large surface area, which could enhance the release of DTX, compared to the AuNR formulation (AL_AuNR_DTX).

\section{Cellular uptake (qualitative and quantitative measurements)}

The cellular internalization of bare nanoparticles and the nanocomposite formulations into B16F10 and MCF-7 cells was assessed qualitatively by flow cytometry and CLSM. The cellular uptake of the bare nanoparticles and nanocomposite formulations was measurable by flow cytometry using the FSC and SSC parameters without the attachment of a fluorescence dye. ${ }^{4-46}$ After treatment, histograms of both cell lines showed overlapping distributions in FSC signals (data not shown). However, a monotonic shift in SSC intensities was observed compared to the control cells because of the intracellular uptake of nanoparticles (Figure 4). The histogram plot indicated that the uptake of uncoated versus lipidcoated nanocomposite formulations significantly differed in terms of particle size and distribution. On the other hand, rhodamine-conjugated lipid-coated gold nanocomposites showed significantly higher fluorescence intensity than the control and bare nanoparticles, confirming nanoparticle uptake. These results indicate that the lipid microenvironment around the nanocomposite formulation could interact with cell membranes to cause cellular uptake. Our result clearly shows the improved cellular uptake of nanoparticles and increased possibility of cellular uptake detection by sidescattering flow cytometry technique of without the addition of fluorescent materials.

We analyzed the cellular uptake of labeled nanocomposite formulations into B16F10 cancer cells by using the live cell imaging abilities of CLSM. Washed cells were incubated with formulations and imaged over time. Figure 5 (A and B) shows the strongest uptake of the rhodamine-attached lipidcoated gold nanocomposites by the cells in red color. The CL_AuNP_DTX formulation containing AuNPs in particular was taken up by cells in a significantly greater quantity than the AL_AuNR_DTX formulation containing 


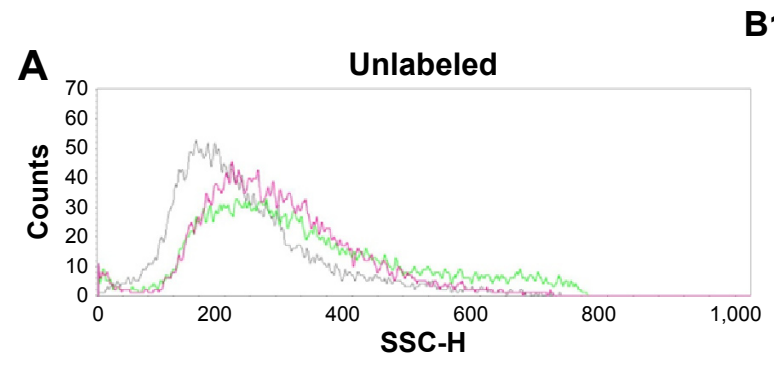

B16F10
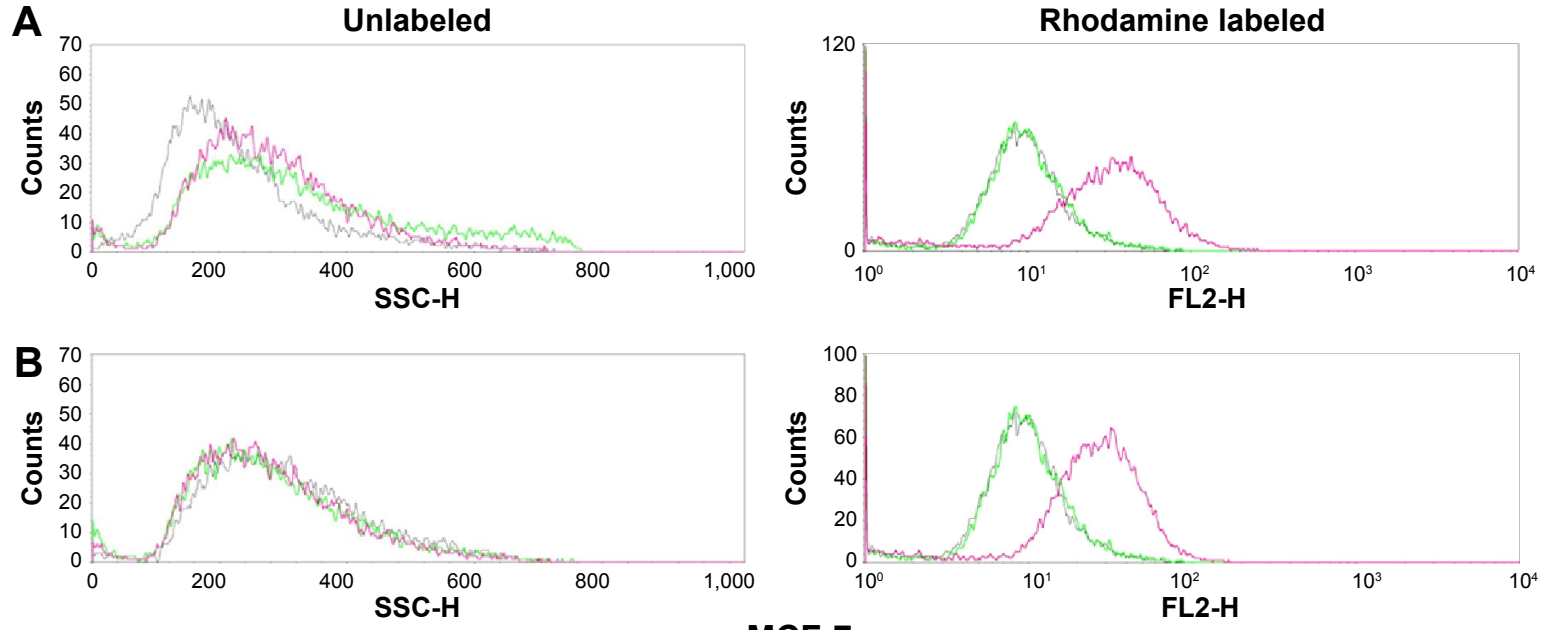

\section{MCF-7}
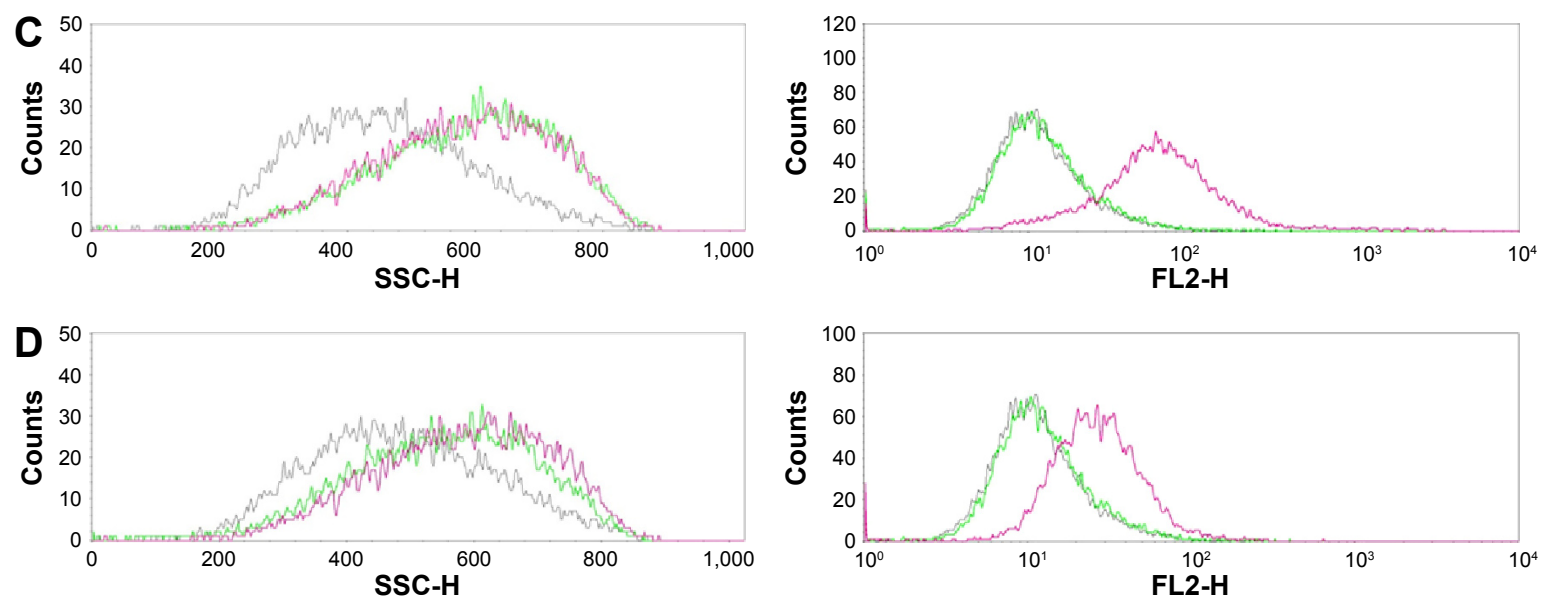

Figure 4 Quantitative cellular uptake analysis by BI6FIO and MCF-7 cells. In vitro cellular uptake of gold nanoparticles and nanocomposite formulations into BI6FI0 (A and B) and MCF-7 cells (C and $\mathbf{D})$, assessed using fluorescence-activated cell sorting analysis.

Notes: Unlabeled and fluorescently labeled histograms of (A) CL_AuNP_DTX and (B) AL_AuNR_DTX for BI6FI0 cells, and (C) CL_AuNP_DTX and (D) AL_AuNR_ DTX for MCF-7 cells. Control, gray; nanoparticles, green; formulations, pink.

Abbreviations: AL_AuNR_DTX, docetaxel-loaded anionic lipid-coated gold nanorod; CL_AuNP_DTX, cationic lipid-coated gold nanoparticle; FL2-H, fluorescence2height; SSC-H, side-scattered light-height.

AuNRs. After the maximal CL_AuNP_DTX uptake, the B16F10 cells underwent morphological changes, followed by apoptosis. In the assessment of AL_AuNR_DTX, less cellular uptake was observed. The nanocomposite formulations entered the cells through endocytosis and accumulated homogeneously in the cytoplasm. Inside the cells, nanoparticles were visualized by the red color. The difference in nanoparticle distribution patterns inside the cells may reflect the differences in nanoparticle surface chemistry and cell differentiation.

The intracellular uptake of DTX in B16F10 and MCF-7 cell lines was compared quantitatively using LC-MS/ MS after exposure to the nanocomposite formulations CL_AuNP_DTX and AL_AuNR_DTX. The cellular uptake of DTX over time from the nanocomposite formulations is presented in Figure 6. The maximum DTX concentrations measured after treatment were $\sim 40$ and $\sim 22 \mathrm{ng} / \mathrm{mL}$ in B16F10 and MCF-7 cells, respectively. There was significantly higher DTX uptake from CL_AuNP_DTX than AL_AuNR_DTX in both cell lines. Different mechanisms could be responsible for the cellular uptake of nanoparticleloaded DTX from both formulations. DTX uptake in B16F10 cells in particular was higher than the uptake from the same formulation group in MCF-7 cells, possibly because of high cluster of differentiation (CD) 44 expression. ${ }^{47}$

Taken together, our data show higher DTX concentrations after 3 hours than when the formulations were introduced into the cells. This could be because most of the cells internalized the formulation initially, and thus further cellular uptake could not occur. 

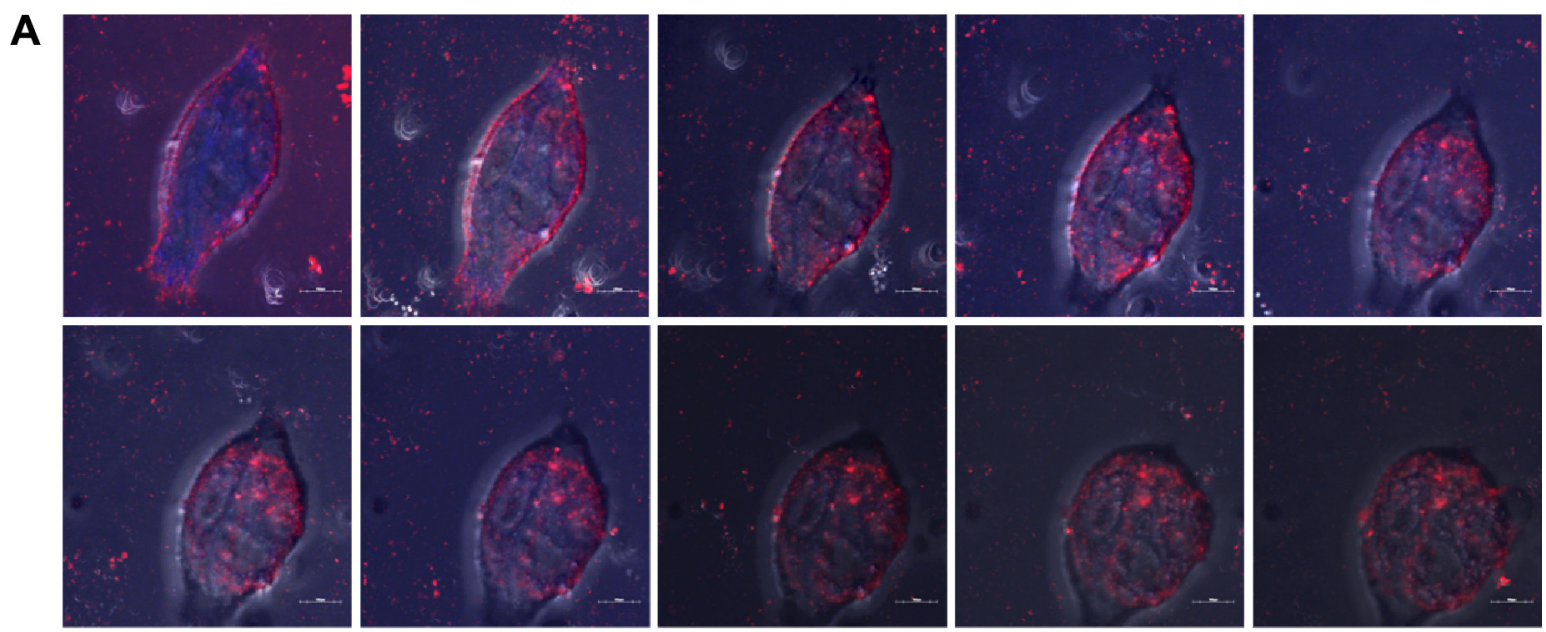

B
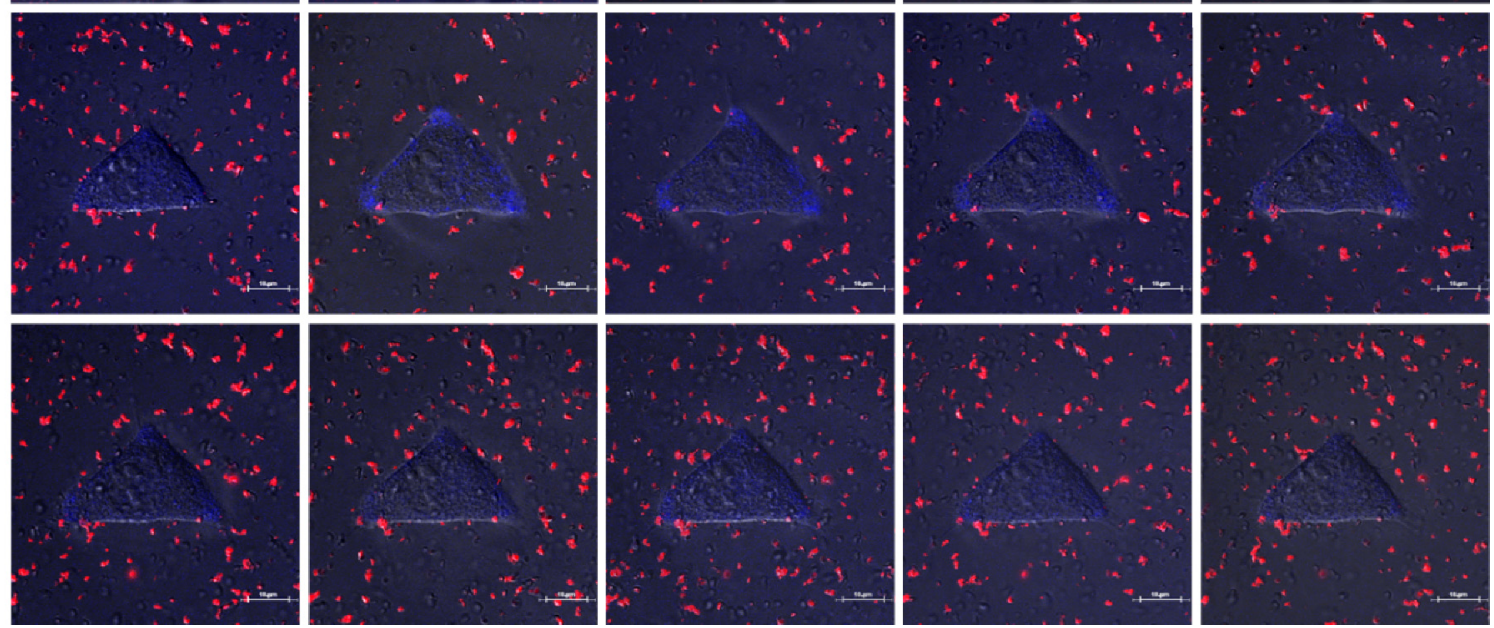

Figure 5 Qualitative study of gold nanocomposites uptake in BI6FI0 cells.

Notes: Confocal laser scanning microscopy analysis of live cell imaging of BI6FI0 cells after treatment with CL_AuNP_DTX (A) and AL_AuNR_DTX (B). Blue, DAPI; red, gold nanocomposites. The scale bars indicate $10 \mu \mathrm{M}$.

Abbreviations: AL_AuNR_DTX, docetaxel-loaded anionic lipid-coated gold nanorods; CL_AuNP_DTX, cationic lipid-coated gold nanoparticles; DAPI, 4',6-diamidino-2phenylindole.
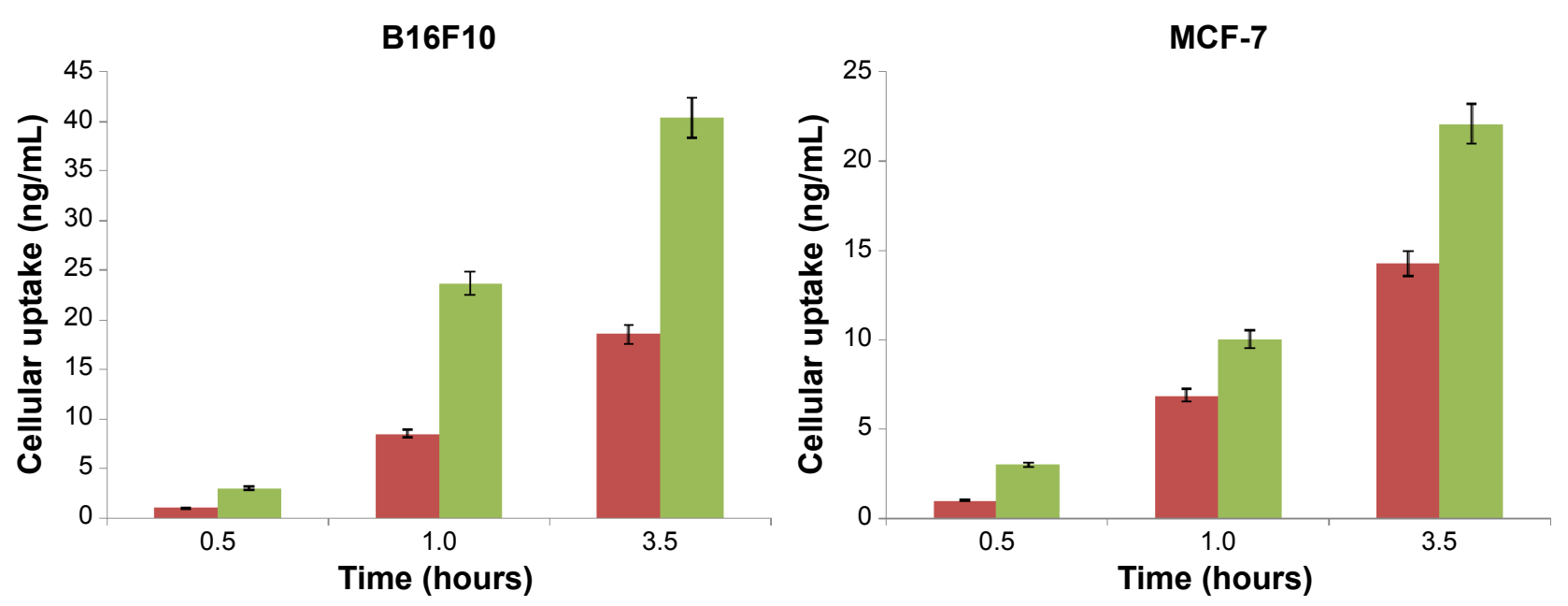

aL_AuNR_DTX $\square$ CL_AuNP_DTX

Figure 6 Quantitative cellular uptake measured by liquid chromatography-tandem mass spectrometry (LC-MS/MS).

Abbreviations: AL_AuNR_DTX, docetaxel-loaded anionic lipid-coated gold nanorod; CL_AuNP_DTX, cationic lipid-coated gold nanoparticle. 


\section{Cytotoxicity (MTT) assay}

The in vitro cytotoxicity of blank liposomes, free DTX, and the DTX-loaded nanocomposite formulations was evaluated in cancer cells by MTT assay after incubation for 24 hours in concentrations ranging from 0.001 to $0.050 \mathrm{nM}$.

Figure 7 shows the percentage viability of B16F10 melanoma cells and MCF-7 breast-cancer cells. Blank liposomes (AL_B and CL_B) showed very low toxicity, with approximately $80 \%$ live cells, thereby providing evidence of the safety and non-toxicity of the lipid coating for drug administration. In contrast, free DTX, the AuNPs, the AuNRs, CL_AuNP_DTX, and AL_AuNR_DTX elicited notable cytotoxicity in both a dose- and time-dependent manner. The AuNPs and AuNRs exhibited measurable toxicity, with cell viability above $65 \%$ observed at all tested concentrations, and the results of the MTT assay revealing that AuNPs are biologically safe. Specifically, the cell-suppression effect of both the CL_AuNP_DTX, and AL_AuNR_DTX formulations was significantly higher than that of free DTX, with higher suppression observed at increasing concentrations of DTX. Our results also show the MCF-7 cell line to be less sensitive to DTX compared to the B16F10 cancer cell line at the same concentration. CL_AuNP_DTX showed comparatively higher toxicity, corroborating other results.

B16F10 and MCF-7 cell lines were exposed to $\mathrm{CL}_{-}$ NP_DTX and AL_AuNR_DTX and incubated for 24 hours (Figure 8). DTX was found to strongly bind and promote microtubule stabilization, leading to mitotic arrest in the cancer cells. Additionally, DTX induces typical Gap 2 (G2)/ Mitosis (M) phase arrest by impairing mitosis and causing chromosomal damage, which corresponds to apoptosis. ${ }^{48,49}$ As seen in our data, most of the control cells were present in the Gap 1 phase, with limited population in the G2/M phase.

\section{B16F10}
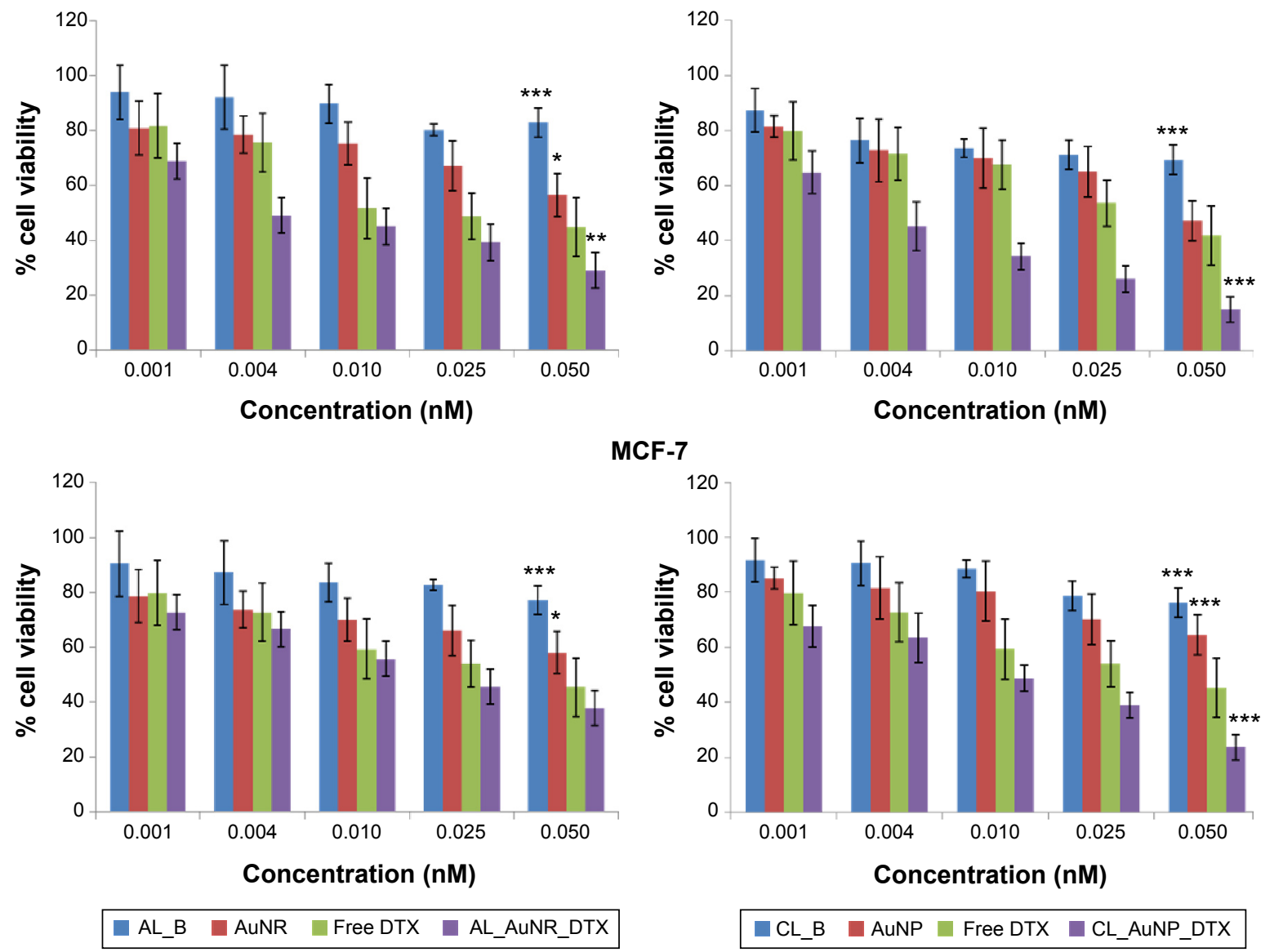

MCF-7

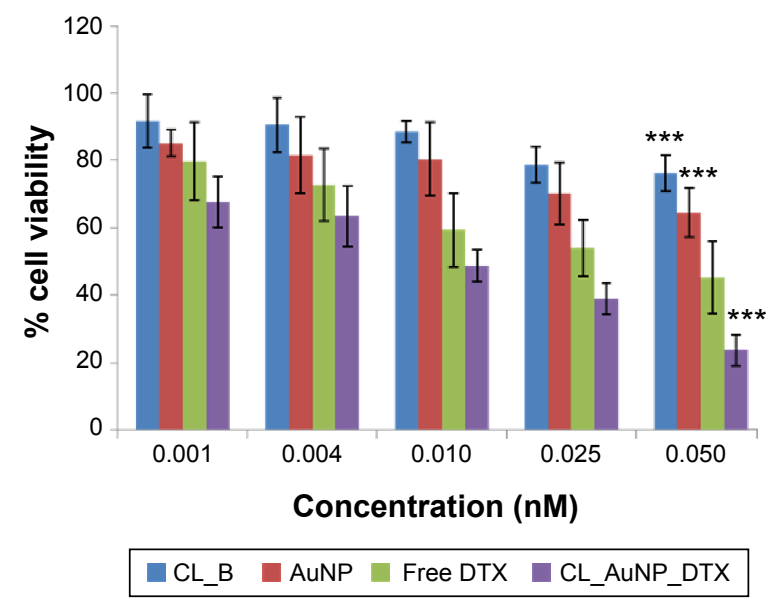

Figure 7 Dose effects study of gold nanocomposites on the cytotoxicity by MTT assay.

Notes: In vitro cytotoxicity of uncoated and lipid-coated drug-containing gold nanocomposites in BI6FI0 and MCF-7 cells after 24 hours. Each value represents the mean \pm standard error $(n=8)$. Statistical significance was determined using two-way analysis of variance with Bonferroni post-tests using free $D T X$ as control $(* P<0.05 ; * * P<0.0$ I; $* * * P<0.001)$.

Abbreviations: AL_AuNR_DTX, docetaxel-loaded anionic lipid-coated gold nanorod; AL_B, anionic liposomes; AuNP, spherical gold nanoparticle; AuNR, gold nanorod; CL_AuNP_DTX, cationic lipid-coated gold nanoparticle; CL_B, cationic liposomes; DTX, docetaxel; MTT, 3-(4,5-dimethylthiazol-2yl)-2,5-diphenyl-2H-tetrazolium bromide. 

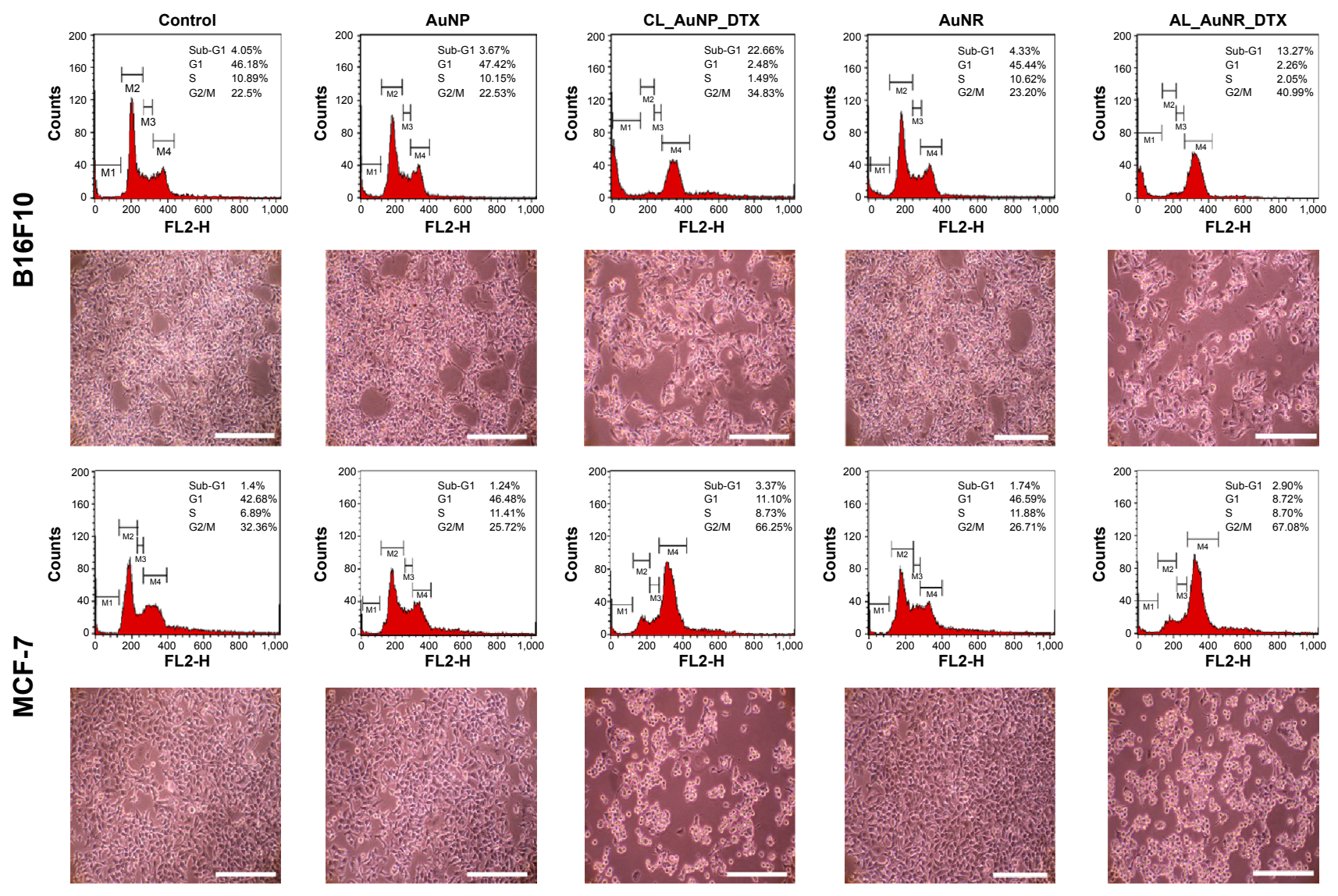

Figure 8 Cell-cycle analysis and the corresponding microscopy images of BI6FI0 and MCF-7 cells after control treatments and 24-hour incubations with AuNP, CL_AuNP_ DTX, AuNR, and AL_AuNR_DTX.

Abbreviations: AuNR, gold nanorod; AuNP, spherical gold nanoparticle; AL_AuNR_DTX, docetaxel-loaded anionic lipid-coated gold nanorod; CL_AuNP_DTX, cationic lipid-coated gold nanoparticle; GI, Gap I; G2/M, Gap 2/Mitosis; S, Synthesis; Sub-GI, Gap I.

The treatment with DTX-loaded nanocomposites, however, resulted in significant $\mathrm{G} 2 / \mathrm{M}$ phase arrest in both the cell lines. Initially, only nanoparticle-treated cells showed minimum G2/M phase arrest, with a lower number of apoptotic cells than the control. Interestingly, DTX-loaded formulations elicited a remarkable increase in $\mathrm{G} 2 / \mathrm{M}$ phase arrest in both cell lines. B16F10 cells, in particular, elicited a remarkable increase in $\mathrm{G} 2 / \mathrm{M}$ phase arrest, corresponding to a significant apoptotic cell population, which indicates the synergistic cytotoxic action of DTX. The corresponding microscopy images may explain the fate of cells after treatment. In B16F10 cells, the CL_NP_DTX formulation showed a high level of cell death as evidenced by reduced cell numbers, whereas, in MCF-7 cells, the formulation caused more round floating cells, which might due to cell-cycle arrest leading to apoptosis. The enhanced cell-cycle arrest followed by apoptosis observed with the CL_NP_DTX formulation may reflect DTX toxicity. The G2/M phase arrest in MCF-7 cell line could be expected to enhance apoptosis with a prolonged incubation time beyond 24 hours.

\section{Conclusion}

We successfully incorporated DTX in AuNPs using a lipid bilayer coating to increase DTX's intracellular delivery and therapeutic efficacy. A conventional thin-film formation, hydration, and sonication method was adopted to produce two lipid-coated DTX-loaded gold nanocomposite formulations with different nanoparticle shapes. The formulation containing spherical-shaped AuNPs (CL_AuNP_DTX) showed maximal drug encapsulation and sustained drug release in a physiological medium. Both formulations $\left(\mathrm{CL}_{-}\right.$ AuNP_DTX and AL_AuNR_DTX) exhibited enhanced cellular uptake and cytotoxicity compared to uncoated AuNPs, AuNRs, and the free drug. CL_AuNP_DTX in particular elicited pronounced cell-cycle arrest of B16F10 and MCF-7 cells in the G2/M phase, with increased population of subGap 1 phase apoptotic cells. Overall, our results suggest that drug-encapsulated lipid-coated individual anisotropic nanoparticles could be used as a promising nanocarrier system for enhanced cancer chemotherapy. We therefore believe that, 
with further optimization and development, this approach could be used in photothermal chemotherapy.

\section{Acknowledgments}

This research was supported by the Basic Science Research Program (NRF2014R1A1A2053373) and the Pioneer Research Center Program (NRF 2014M3C1A3054153) of the National Research Foundation of Korea and was funded by the Ministry of Education, Science and Technology.

\section{Disclosure}

The authors declare no conflicts of interest in this work.

\section{References}

1. Feng SS. New-concept chemotherapy by nanoparticles of biodegradable polymers: where are we now? Nanomedicine (Lond). 2006;1(3): 297-309.

2. Muthu MS, Feng SS. Nanopharmacology of liposomes developed for cancer therapy. Nanomedicine (Lond). 2010;5(7):1017-1019.

3. ElBayoumi TA, Torchilin VP. Current trends in liposome research. Methods Mol Biol. 2010;605:1-27.

4. Lasic DD, Papahadjopoulos D. Medical Applications of Liposomes. Amsterdam: Elsevier Science; 1998.

5. Feng SS, Ruan G, Li QT. Fabrication and characterizations of a novel drug delivery device liposomes-in-microsphere (LIM). Biomaterials. 2004;25(21):5181-5189.

6. Murphy CJ, Sau TK, Gole AM, et al. Anisotropic metal nanoparticles: Synthesis, assembly, and optical applications. J Phys Chem B. 2005; 109(29):13857-13870.

7. Burda C, Chen X, Narayanan R, El-Sayed MA. Chemistry and properties of nanocrystals of different shapes. Chem Rev. 2005;105(4): $1025-1102$

8. Shaw CP, Fernig DG, Lévy R. Gold nanoparticles as advanced building blocks for nanoscale self-assembled systems. J Mater Chem. 2011; 21(33): 12181-12187.

9. Jain PK, Huang X, El-Sayed IH, El-Sayed MA. Review of some interesting surface plasmon resonance-enhanced properties of noble metal nanoparticles and their applications to biosystems. Plasmonics. 2007; 2(3):107-118.

10. Huang X, Jain PK, El-Sayed IH, El-Sayed MA. Plasmonic photothermal therapy (PPTT) using gold nanoparticles. Lasers Med Sci. 2008; 23(3):217-228.

11. Yi DK. A study of optothermal and cytotoxic properties of silica coated Au nanorods. Mater Lett. 2011;65(15):2319-2321.

12. Tong L, Wei Q, Wei A, Cheng JX. Gold nanorods as contrast agents for biological imaging: optical properties, surface conjugation and photothermal effects. Photochem Photobiol. 2009;85(1):21-32.

13. Boisselier E, Astruc D. Gold nanoparticles in nanomedicine: preparations, imaging, diagnostics, therapies and toxicity. Chem Soc Rev. 2009; 38(6):1759-1782.

14. Rasch MR, Rossinyol E, Hueso JL, Goodfellow BW, Arbiol J, Korgel BA. Hydrophobic gold nanoparticle self-assembly with phosphatidylcholine lipid: membrane-loaded and janus vesicles. Nano Lett. 2010;10(9): 3733-3739.

15. Chen Y, Bose A, Bothun GD. Controlled release from bilayerdecorated magnetoliposomes via electromagnetic heating. ACS Nano. 2010;4(6):3215-3221.

16. Ahmed S, Madathingal RR, Wunder SL, Chen Y, Bothun G. Hydration repulsion effects on the formation of supported lipid bilayers. Soft Matter. 2011;7(5):1936-1947.

17. Von White G 2nd, Chen Y, Roder-Hanna J, Bothun GD, Kitchens CL. Structural and thermal analysis of lipid vesicles encapsulating hydrophobic gold nanoparticles. ACS Nano. 2012;6(6):4678-4685.
18. Wijaya A, Hamad-Schifferli K. High-density encapsulation of Fe3O4 nanoparticles in lipid vesicles. Langmuir. 2007;23(19):9546-9550.

19. Xia T, Rome L, Nel A. Nanobiology: particles slip cell security. Nat Mater. 2008;7(7):519-520.

20. Nikoobakht B, El-Sayed MA. Preparation and growth mechanism of gold nanorods (NRs) using seed-mediated growth method. Chem Mater. 2003;15(10):1957-1962.

21. Sau TK, Murphy CJ. Seeded high yield synthesis of short Au nanorods in aqueous solution. Langmuir. 2004;20(15):6414-6420.

22. Grabar KC, Freeman RG, Hommer MB, Natan MJ. Preparation and characterization of Au colloid monolayers. Analytical chemistry. 1995; 67(4):735-743

23. Sutherland WS, Winefordner JD. Colloid filtration: a novel substrate preparation method for surface-enhanced Raman spectroscopy. $J$ Colloid Interface Sci. 1992;148(1):129-141.

24. Liu X, Huang N, Li H, Jin Q, Ji J. Surface and size effects on cell interaction of gold nanoparticles with both phagocytic and nonphagocytic cells. Langmuir. 2013;29(29):9138-9148.

25. Zhu Y, Ramasamy M, Yi DK. Antibacterial activity of ordered gold nanorod arrays. ACS Appl Mater Interfaces. 2014;6(17):15078-15085.

26. Frens G. Controlled nucleation for the regulation of the particle size in monodisperse gold suspensions. Nature. 1973;241(105):20-22.

27. Orendorff CJ, Alam TM, Sasaki DY, Bunker BC, Voigt JA. Phospholipid-gold nanorod composites. ACS Nano. 2009;3(4):971-983.

28. Ruttala HB, Ko YT.Liposome encapsulated albumin-paclitaxel nanoparticle for enhanced antitumor efficacy. Pharm Res. 2014;32(3):1002-1016.

29. Chowdhury S, Burbridge S, Harper P. Chemotherapy for the treatment of hormone-refractory prostate cancer. Int J Clin Pract. 2007;61(12): 2064-2070.

30. Fulton B, Spencer CM. Docetaxel. Drugs. 1996;51(6):1075-1092.

31. Bothun GD. Hydrophobic silver nanoparticles trapped in lipid bilayers: Size distribution, bilayer phase behavior, and optical properties. J Nanobiotechnology. 2008;6:13.

32. Labouta HI, Hampel M, Thude S, Reutlinger K, Kostka KH, Schneider M. Depth profiling of gold nanoparticles and characterization of point spread functions in reconstructed and human skin using multiphoton microscopy. J Biophotonics. 2012;5(1):85-96.

33. Paciotti GF, Myer L, Weinreich D, et al. Colloidal gold: a novel nanoparticle vector for tumor directed drug delivery. Drug Deliv. 2004;11(3):169-183.

34. Park SH, Oh SG, Mun JY, Han SS. Loading of gold nanoparticles inside the DPPC bilayers of liposome and their effects on membrane fluidities. Colloids Surf B Biointerfaces. 2006;48(2):112-118.

35. Sperling RA, Gil PR, Zhang F, Zanella M, Parak WJ. Biological applications of gold nanoparticles. Chem Soc Rev. 2008;37(9):1896-1908.

36. Reum N, Fink-Straube C, Klein T, Hartmann RW, Lehr CM, Schneider M. Multilayer coating of gold nanoparticles with drug-polymer coadsorbates. Langmuir. 2010;26(22):16901-16908.

37. Nam J, Ha YS, Hwang S, et al. pH-responsive gold nanoparticles-inliposome hybrid nanostructures for enhanced systemic tumor delivery. Nanoscale. 2013;5(21):10175-10178.

38. Hobbs SK, Monsky WL, Yuan F, et al. Regulation of transport pathways in tumor vessels: role of tumor type and microenvironment. Proc Natl Acad Sci U S A. 1998;95(8):4607-4612.

39. Yuan F, Dellian M, Fukumura D, et al. Vascular permeability in a human tumor xenograft: molecular size dependence and cutoff size. Cancer Res. 1995;55(17):3752-3756.

40. Zhai G, Wu J, Zhao X, et al. A liposomal delivery vehicle for the anticancer agent gossypol. Anticancer Res. 2008;28(5A):2801-2805.

41. Liu D, Liu Z, Wang L, Zhang C, Zhang N. Nanostructured lipid carriers as novel carrier for parenteral delivery of docetaxel. Colloids Surf B Biointerfaces. 2011;85(2):262-269.

42. Engels FK, Mathot RA, Verweij J. Alternative drug formulations of docetaxel: a review. Anticancer Drugs. 2007;18(2):95-103.

43. US Environmental Protection Agency (EPA). Nanomaterial Case Studies: Nanoscale Titanium Dioxide. External review draft. EPA/600/R09/057US. Research Triangle Park, NC: US EPA; 2009. Available from: http://ofmpub.epa.gov/eims/eimscomm.getfile?p_download_ id $=490825$. Accessed July 15, 2015. 
44. Salzman GC. Light scatter: detection and usage. Curr Protoc Cytom. 2001; Chapter 1:Unit 1.13.

45. Shapiro HM. Practical Flow Cytometry. 4th edition. Hoboken, NJ: Wiley; 2003.

46. Stringer B, Imrich A, Kobzik L. Flow cytometric assay of lung macrophage uptake of environmental particulates. Cytometry. 1995; 20(1):23-32.
47. Cho HJ, Yoon HY, Koo H, et al. Self-assembled nanoparticles based on hyaluronic acid-ceramide (HA-CE) and Pluronic ${ }^{\circledR}$ for tumor-targeted delivery of docetaxel. Biomaterials. 2011;32(29):7181-7190.

48. Downing KH, Nogales E. Tubulin and microtubule structure. Curr Opin Cell Biol. 1998;10(1):16-22.

49. Miller ML, Ojima I. Chemistry and chemical biology of taxane anticancer agents. Chem Rec. 2001;1(3):195-211.
International Journal of Nanomedicine

\section{Publish your work in this journal}

The International Journal of Nanomedicine is an international, peerreviewed journal focusing on the application of nanotechnology in diagnostics, therapeutics, and drug delivery systems throughout the biomedical field. This journal is indexed on PubMed Central, MedLine, CAS, SciSearch ${ }^{\circledR}$, Current Contents ${ }^{\circledR} /$ Clinical Medicine,

\section{Dovepress}

Journal Citation Reports/Science Edition, EMBase, Scopus and the Elsevier Bibliographic databases. The manuscript management system is completely online and includes a very quick and fair peer-review system, which is all easy to use. Visit http://www.dovepress.com/ testimonials.php to read real quotes from published authors.

\footnotetext{
Submit your manuscript here: http://www.dovepress.com/international-journal-of-nanomedicine-journal
} 